
\title{
25 Research Square \\ Bioinformatics Analysis and Insights for The Role of COMMD7 in Hepatocellular Carcinoma
}

\section{Xuehui Peng}

Army Medical University

Yonggang $\mathrm{He}$

Army Medical University

Xiaobing Huang

Army Medical University

Nan You

Army Medical University

Huiying Gu

Army Medical University

\section{Rui Dong}

Army Medical University

Xiaomin Yang

Army Medical University

Lu Zheng

Army Medical University

Jing Li ( xqyylj@163.com )

Army Medical University

Research article

Keywords: COMMD7, Hepatocellular carcinoma, tumor progression, NF-KB, CXCL10

Posted Date: October 6th, 2020

DOI: https://doi.org/10.21203/rs.3.rs-79438/v1

License: (c) (1) This work is licensed under a Creative Commons Attribution 4.0 International License.

Read Full License 


\section{Abstract}

Background: The tumorigenesis and development of hepatocellular carcinoma (HCC) is a process involving multiple factors. The COMMDs family proteins were reported to play important roles in various disease and cancers including HCC. We previously found COMMD7 acted as a HCC-promotion factor; however, further understanding on COMMD7 was needed. We conducted these bioinformatics analysis for the purpose of comprehensive understanding of the functional role of COMMD7 in HCC.

Methods: The bioinformatics analysis of COMMD7 were launched by online platforms including KEGG, GEPIA, cBioportal, Gene Ontology and The Kaplan-Meier plotter. Data from The Cancer Genome Atlas (TCGA) and Genotype-Tissue Expression (GTEx) were downloaded, and the data analysis and processing were conducted by RStudio (version 1.3.959) software.

Results: The expression profile results of COMMD7 in TCGA and GTEx database suggested that COMMD7 expressed highly in liver tumor tissues and positively related with poorer prognosis $(p<0.01)$; COMMD7 also contributed to the early development of HCC as its higher expression resulted in progression from stage I to stage III $(p<0.01)$. Based on our previous studies, COMMD7 may target NF-KB signaling and CXCL10 to enhance the proliferation of hepatoma cells so that promoting the development of HCC.

Conclusions 2 This study updates the current studies about the newly recognized roles of COMMD7 in the progression of HCC, summarizing the research progress and prospects of COMMD7 comprehensively, offering an outlook for the future investigation and targeted therapy of HCC.

\section{Background}

Chronic liver disease and primary liver cancer are a massive global problem, as the most prevalent form of primary liver cancer, hepatocellular carcinoma is a global pandemic with a significant increase in morbidity and mortality worldwide[1]. Recent epidemiology statistical data confirms that HCC represents the fourth leading cause of cancer-related death and ranks sixth in terms of new cases worldwide[2]. With a poor 5-year survival, liver cancer is the second most lethal tumor after pancreatic cancer[3].The tumorigenesis and development of HCC is a complex process involving multiple genes and factors[4] (Fig. 1). It has been reported that the mutation of p53[5], AKT/ $\beta$-catenin[6], HFE[7], TSC1/2[8] and MBL[9] genes were frequently occurred in aggressive HCC. Meanwhile, the activation of these genes such as mTOR, PI3K, MAP kinase, STAT3, JAK were proved to be related with the progression of HCC[10-13]. Recently, metabolism reprogramming is also confirmed to behave distinctly in different periods of HCC[14-16].

The COpper Metabolism MURR1 Domain-containing (COMMD) family consists of ten members ranging from COMMD1 to COMMD10, which is characterized by a highly conservative COMM domain at the carboxyl terminal[17]. The COMMDs family members have been frequently reported to involve in human disease and cancers (Table 1). For example, the most researched COMMD1 induces apoptosis in human 
lung cancer cells by inhibition of NF-KB signaling[18, 19].COMMD1 disrupts HIF-1a/ $\beta$ dimerization and inhibits human tumor cell invasion[20], and downregulation of COMMD1 promotes tumor development by modulating a positive feedback loop that amplifies inflammatory and stemness-associated properties of cancer cells. COMMD3/8 complex selectively recruited GRK6 and induced GRK6-mediated phosphorylation of the receptor and activation of $\beta$-arrestin-mediated signaling thus regulates immune response[21]. COMMD4 was defined as an anti-cancer therapeutic target and prognostic factor in nonsmall cell lung cancer[22]. COMMD5 acts as an adaptor protein to coordinate endosomal trafficking and plays an important role inEGFR transporting and activity in renal cell carcinoma[23]. COMMD6 may modulate the ubiquitination and degradation of NF-KB subunits and regulate ribonucleoprotein and spliceosome complex biogenesis in tumors[24]. COMMD9 participates in TFDP1/E2F1 activation and plays a critical role in non-small cell lung cancer[25]. COMMD10 may play a tumor suppressive role in renal clear cell carcinoma through the miR-590-3p-COMMD10-Cul2-RBX1-NF-KB/HIF/NRF2 pathway and regulate the chemotherapy resistance of various tumor cells to cisplatin[26, 27].In addition, the COMMDs family proteins also regulates plasma LDL Levels and attenuates atherosclerosis through forming COMMD/CCDC22/CCDC93 to stabilize the CCC complex in endosomal LDLR trafficking[28].

As a key member of COMMDs family, COMMD7 consists of 200 amino acids and located on the 20th chromosome. Yet the bio-function of COMMD7 was rarely reported. Goodall et al, found that the SNP of COMMD7 may associated with platelet function of FC and PC[29]. While Bajuna Rashid Salehe confirmed the association of the SNP rs6141803 of COMMD7 with cardiovascular diseases (CVDs) by interfering platelet function[30]. Our preliminary research revealed that COMMD7 was highly expressed in hepatocellular carcinoma and might play as an oncogenic role in $\mathrm{HCC}$, and it may promote HCC through activating NF-KB signaling by regulating the expression of chemokine CXCL10.

In this study, we firstly launched the expression profile data and bioinformatics analysis of COMMD7 in $\mathrm{HCC}$, combining with recent studies, we summarized the functional role of COMMD7 comprehensively, providing an overview for the latest research advances of it, which may help to direct targeted therapy of HCC.

\section{Methods}

\section{GEPIA2 (Gene Expression Profiling Interactive Analysis) dataset}

GEPIA2 is an updated and enhanced version of GEPIA web server which features 198619 isoforms and 84 cancer subtypes based on tumor and normal samples from the TCGA and the GTEx databases, exhibiting a gene signature quantification by single-cell sequencing studies, and provides tools such as correlation analysis and survival analysis[31, 32].

\section{The Kaplan-Meier plotter}


The prognostic value of COMMD7 mRNA expression was evaluated by an online database, Kaplan-Meier Plotter (https://kmplot.com/), which contains gene expression data and survival information of 364 clinical liver cancer patients (https://kmplot.com/analysis/index.php?p=service\&cancer=liver_rnaseq) [33].Toanalyze the overall survival (OS), progression-free survival (PFS), and recurrence-free survival (RFS) of patients with liver cancer. COMMD7 was loaded as the only gene symbol, patient samples were split into two groups (high expression vs. Low expression) and assessed by a Kaplan-Meier survival plot, with the hazard ratio (HR) with 95\% confidence intervals (Cl) and logrank p value.

\section{TCGA data and cBioPortal}

The Cancer Genome Atlas (TCGA) contains both sequencing and pathological data on 30 different cancers[34]. The hepatocellular carcinoma (TCGA, firehose legacy) dataset including data from 373 cases with pathology reports was selectedfor further analysis of COMMD7 using cBioPortal (http://www.cbioportal.org). Thegenomic profiles included mutations, mRNA expression z-scores (RNA Seq V2 RSEM) and protein expression Z-scores. Co-expression and correlations among COMMD7 and other COMMDs family members were calculated according to the cBioPortal's online instruction.

\section{Statistical analysis}

RStudio is a powerful data processing tool and is frequently applied in bioinformatics analysis[35]. The data from TCGA were processed and analyzed by RStudio, and heatmap drawing of COMMD7 with other COMMDs family members were conducted in $\mathrm{R}$ (version 4.0.0, $\mathrm{R}$ Development Core Team) within the RStudio platform (version 1.3.959).

\section{DAVID and Gene Ontology}

We conducted Gene Ontology (GO) of significantly deferentially expressed genes (SDEGs) after COMMD7 was knocked down using DAVID v6.8 online server (https://david.ncifcrf.gov/conversion.jsp), including molecular functions (MF), cellular components (CC), and biologic process (BP).

\section{Results}

\section{Expression profile of COMMD7 in patients with HCC}

In order to understand the expression profile of COMMD7 in liver cancer, we performed bioinformatics analysis of COMMD7. As shown in Fig. 2, according to the 369 liver cancer tissues and 160 normal tissues included in Gene Expression Profiling Interactive Analysis (GEPIA) dataset (http://gepia2.cancerpku.cn/), the mRNA expression level of COMMD7 in liver cancer tissues is much higher, as the transcripts per million (TPM) in tumor tissues was nearly 1.5 times higher than in normal tissues $(p<0.01$; Fig. $2 a)$. The protein relative expression level of COMMD7 in tumors and non-tumors was consistent with that of mRNA (Fig. 2b). Further, we detected the expression dynamic changes of COMMD7 during the development of HCC. The results showed that the expression of COMMD7 gradually increased from 
stage I to stage III $(p<0.01)$, indicating that COMMD7 was closely related with the early progression of HCC (Fig. 2C).

Our team also clarified that COMMD7 was highly expressed in liver cancer tissue specimens. We verified the correlation of COMMD7 with early stage of HCC by detecting the mRNA expression level of COMMD7 in 68 pairs of liver cancer and adjacent tissues[36]. Subsequently, a self-prepared monoclonal antibody to COMMD7 was uesd to detect the protein level of COMMD7 in 7 liver cancer cell lines including HepG2, Huh7, Hep3B, HLE, HLF, SK-Hep-1 and PLC/PRF5. The results revealed that COMMD7 protein expressed totally higher in these hepatoma cells than in normal hepatocytes, especially in HepG2 and SK-Hep-1 [36, 37]. For further study, we constructed a pGenesil-COMMD7-shRNA plasmid both in HepG2 and SK-Hep1 cells by means of short-hairpin RNA targeted technology. As a result, silence of COMMD7 significantly reduced cell proliferation and colony formation, while increased apoptosis and led to cell cycle arrest at Sphase in both two cell lines[38].

\section{Association of increased mRNA of COMMD7 with poor prognosis of patients with HCC}

We further explored the critical efficiency of COMMD7 in the survival of patients with HCC. Kaplan-Meier Plotter tools were used to analyze the correlation between the mRNA level of COMMD7 and the survival of $364 \mathrm{HCC}$ patients in the database (http://kmplot.com/analysis/index.php?p=service\&cancer=liver). The Kaplan-Meier curve and log-rank test analysis revealed that the increased mRNA level of COMMD7 was significantly associated with lower overall survival (OS) and recurrence-free survival (RFS) $(p<0.01)$ (Fig. 3) in patients with HCC.

\section{Gene mutation and co-expression analysis of COMMD7 in HCC}

We analyzed COMMD7 gene alterations, expression correlation of COMMDs family members, and coexpression genes of COMMD7 by using the cBioPortal online tool for hepatocellular carcinoma (TCGA, Firehose Legacy, http://www.cbioportal.org/ ). AS a result, COMMD7 was altered in 41 samples out of 373 patients with HCC (11\%) (Fig. 4a), and the altered group obtained better overall survival (median month overall survival $81.67 \mathrm{Vs} 53.35$, Fig. $4 \mathrm{~b}$ and $4 \mathrm{c}$ ). We also calculated the mRNA expression correlations of COMMD7 and other COMMDs family members with each other by Pearson's correction. The results indicated that most of the COMMDs family members were expressed positively with COMMD7, however the expression of COMMD2 and COMMD10 were negatively correlated with COMMD7 (Fig. 4d).

Co-expression gene analysis results signified that the top 10 genes such as DNYLRB1, PDRG1, MANBAL, PFDN4, RALY were positively related with COMMD7 in HCC patients $(p<0.01)$, most of these genes were located on chromosome 20, which may be due to COMMD7 was also located on that chromosome (Table 2). The top 10 negatively related genes were ABHD18, ERN1, DDI2, USP12, METTL14, TOR1AIP2, 
PPTC7, MAP3K2, RSC1A1, ZNF281 $(p<0.01)$. However, those negatively related genes distributed randomly in chromosome1, 2, 4, 12, 13, and 17 (Table 3 ).

\section{Functional analysis of COMMD7 in liver cancer stem cells}

We have previously knocked down COMMD7 gene in liver cancer stem cells (LCSCs) to observe the effect of COMMD7 in LCSCs. After gene-sequencing, we analyzed the function of COMMD7 by Gene Ontology (GO) in the Database for Annotation, Visualization, and Integrated Discovery (DAVID, https://david.ncifcrf. gov/ summary. jsp), the go enrichment including biological processes (BP), cellular components (CC), and molecular functions (MF) were launched. We found that GO:0055114 (oxidation-reduction process), GO:0098590 (plasma membrane region), G0:0070742 (C2H2 zinc finger domain binding) were most enriched for up-regulated genes after COMMD7 knock-down, while G0:0007399 (nervous system development), GO:0031012 (extracellular matrix), GO:0005509 (calcium ion binding) were significantly enriched for down-regulated genes(Fig. 5), indicating that COMMD7 may mainly combined with targeted domain or ions to exert its functional effect.

\section{Discussion}

The bioinformatics analysis results suggested that COMMD7 expressed highly in liver tumor tissues, which donating poor prognosis and early progression of HCC. Since current studies on COMMD7 and HCC was primarily carried out in our center, herein we discussed the potential molecular mechanism by reviewing our previous work and research advances about COMMD7.

\section{COMMD7 enhanced hepatoma cell proliferation through activating NF-KB signaling}

The nuclear factor of $\mathrm{k}$-light-chain-enhancer of activated B cells (NF-KB) transcription factor is well-known for its pivotal role in the maintenance of cellular homeostasis including cell death and apoptosis, inflammation and immunity[39]. Dysregulation of NF-KB pathway is frequently found in common human disease, and it is usually in a state of continuous activation in most cancers including Leukemia[40], lung cancer, $\mathrm{HCC}[41,42]$. The classical activation of NF-KB needs the $26 \mathrm{~s}$ proteasome induced ubiquitination and degradation of IKBa, NF-KB is then released from the cytoplasmic NF-KB/lkBa complex, and exposing the nuclear localization domain, forming a p50/RelA dimer, activating the transcription of tumor-related factors downstream. Additionally, NF-KB also can be activated in other ways such as nucleolar stress, tumor necrosis factor receptor (TNFR) family ligands CD40L[43], ROS[44], and angiotensin[45]. Thus the inhibition of NF-KB activity is considered to be one promising strategy to manipulate the tumorigenesis and development of cancers.

The COMMDs family member COMMD1 has been widely reported to facilitate the ubiquitination of NF-KB subunit RelA and its subsequent proteasomal degradation, therefore down-regulates NF-kB activity as well as the transcription of its targeted cancer-related genes downstream[19], hence COMMD1 negatively regulates the inflammatory responses and acts as an anti-inflammatory effector to repress colitis- 
associated cancers[46] and even as a tumor suppressor[47] in certain cancers such as prostate cancer[48] and lung cancer[18]. While in our previous studies, we found that COMMD7 is positively related to the expression and activation of NF-KB in HCC. An analysis of the expression relationship between COMMD1 and COMMD7 also showed their negative correlation $(R=-0.6237, p<0.001)$.

Furthermore, COMMD7 may be correlated with NF-kB through a positive feedback loop. Scilicet on one hand NF-KB directly binds to the promoter 1, 4, 5 and 6 sites of COMMD7, suggesting that NF-KB could target to COMMD7 and directly regulate its transcription in hepatocellular carcinoma cells[49]; on the other hand, COMMD7 silence in HepG2 cells resulted in 75\% inhibition rate of NF-KB, indicating that COMMD7 conversely regulates the nuclear translocation of NF-KB as well as the transcriptions of consequent genes involved in $\mathrm{HCC}[38]$. While how COMMD7 regulates the activity of NF-KB need further study. You et al, demonstrated that oxidative stress was required for COMMD7-mediated NF-KB activation since they found that overexpression of COMMD7 augmented intracellular ROS level and p65 phosphorylation in Huh7 cells[50]. Meanwhile, recent study manifested that COMMD7 activates NF-KB by upregulating protein inhibitor for activated stat4 (PIAS4) in $\mathrm{Nanog}^{+}$hepatocellular carcinoma stem cells to maintain its proliferation and metastasis[51].

\section{COMMD7 promoted HCC progress and metastasis by modulating the production of CXCL10}

The role of immune system in tumor has been in the spotlight, cancer immunotherapy turns into hot issue. Chemokines are a class of small cytokines or signaling proteins secreted by cells which induce directional chemotaxis of vicinity response cells, these low-molecular-weight cytokines range from $8 \mathrm{kDa}$ to $10 \mathrm{kDa}$ are of critical importance in tumor immune response. C-X-C motif chemokine ligand 10 (CXCL10) belongs to interferon- $\gamma$ (INF- $\gamma$ ) inducible chemokine family which orchestrates leukocyte trafficking and modulate innate and adaptive immune responses and exerts its biological function by binding with CXCR3 receptor[52]. The role of CXCL10 in cancers and disease remains controversial, although it has been reported to suppress tumor by interferon- $y$-mediated anti-tumor effect[53], more and more researches revealed it was beneficial for tumor growth, metastasis and recurrence. High serum level of CXCL10 could be a potential biomarker for many kinds of disease such as rheumatoid arthritis[54], psoriasis[55], CGVHD[56] and the CXCL10/CXCR3 axis mediates lung cancer cell migration[57]. Besides, expression of CXCL10 positively correlates with obesity and type 2 diabetes and linked to poor outcomes after islet transplantation[58]. In hepatocytes and liver cancer, CXCL10 was proved to enhance HCV and male HBV infection[59], the CXCL10/CXCR3 signaling promotes liver tumor growth via recruiting more endothelial progenitor cell (EPC) and inducing their mobilization, differentiation and neovessel formation[60]. Likewise, CXCL10 upregulated at liver graft injury directly induced the mobilization and intragraft recruitment of Tregs, which further promoted HCC recurrence after transplantation [61]. Moreover, immune checkpoint inhibitor (ICl) therapy targeting anti-programmed cell death-1 (anti-PD-1) or its ligand (anti-PD-L1) is the backbone of numerous combination regimens aimed at improving the objective response and survival of patients with HCC[62], and Chow's recent study illustrated that CXCL10 
is required for PD-1 blocked therapy responders[63]. Taken together, targeting CXCL10 may attenuate early HCC progression and recurrence.

Interestingly, our present study discovered that CXCL10 dramatically upregulated in COMMD7 overexpressed Huh7 cell line, and the expression levels of CXCL10 in other HCC cell lines including HepG2, Hep3B and HLE have been detected to be consistent with the expression level of COMMD7. In addition, inhibition of CXCL10 impaired COMMD7 mediated HCC cell proliferation and metastasis, indicating that COMMD7 positively regulates CXCL10 production in HCC[64]. Further, it has been reported that NF-KB directly binds to the promoter site of CXCL10 and regulates its expression [65]. For example, the activation NF-KB is required for the induction of CXCL10 during the progress and metastasis of Melanoma[66] and breast cancer[67]. Given that our previous evidence demonstrated that COMMD7 participated in NF-KB activation, therefore it probably promoted CXCL10 production by activating NF-KB, and the subsequent research also proved it[50]. Overall, these researches expounded that COMMD7 could strengthen HCC progress and metastasis by modulating the production of CXCL10 via NF-KB activation.

\section{Conclusions}

In summary, we illuminated the expression profile of COMMD7 in hepatoma cell lines and human liver tumor tissues, shedding light on the promoting effect of COMMD7 on HCC. The results further highlight that high expression of COMMD7 is related with the early progression of $\mathrm{HCC}$ and poor prognosis. More importantly, it plays a pivotal role in hepatoma cell proliferation and metastasis through activating NF-KB signaling and CXCL10 via PIAS4 and ROS. In conclusion, since these bioinformatics analysis results and researches direct the positive correlation of COMMD7 high expression with $\mathrm{HCC}$, it is possible to be regarded as a potential biomarker for the prevention and treatment of HCC. However how COMMD7 interacts with these effectors and more detailed mechanism warrants further investigation.

\section{Abbreviations}

$\mathrm{HCC}$

Hepatocellular carcinoma; COMMD7:copper metabolism MURR1 domain-containing protein 7; HCC:hepatocellular carcinoma; TCGA:The Cancer Genome Atlas; GTEx:Genotype-Tissue Expression; NFKB:nuclear factor of $\mathrm{K}$-light-chain-enhancer of activated B cells; CXCL10:C-X-C motif chemokine ligand 10; INF-ү:interferon-ү; ROS:reactive oxygen species; PIAS4:protein inhibitor for activated stat4. PD1:programmed cell death-1.

\section{Declarations}

\section{Ethics approval and consent to participate}

This study was approved by the Ethics Committee of the Second Affiliated Hospital of Army Medical University, PLA. All the data were retrieved from online databases and published literatures, therefore it 


\section{Consent for publication}

Not applicable.

\section{Availability of data and materials}

The supporting materials and data of this review has been included within the article.

\section{Competing interests}

The authors declare that they have no conflicts of interests.

\section{Funding}

This work was supported by National Natural Science Foundation of China (contract grants No.81672902), Basic Science and Frontier Technology Research Project of Chongqing (No.cstc2017jcyjAX0348), Science and Technology Plan Project of Chongqing (No.cstc2017jcyjyszxX0002).

\section{Author contributions}

Lu Zheng and Jing Li: Study design and guidance; Xuehui Peng and Yonggang He: Analyzing the data and drafting the manuscript; Xiaobing Huang, Nan You and Huiying Gu have participated in the previous research work of COMMD7; Rui Dong and Xiaomin Yang contributed to data acquisition. All authors read and approved the final version of the manuscript.

\section{Acknowledgements}

We sincerely acknowledge Ping Liang and Ye Tan for the previous research work about COMMD7 they had participated, and thank the $\mathrm{R}$ development core team for their bioinformatic technology support.

\section{References}

1. Loomba R, Lim JK, Patton H, El-Serag HB. AGA Clinical Practice Update on Screening and Surveillance for Hepatocellular Carcinoma in Patients With Nonalcoholic Fatty Liver Disease: Expert Review. Gastroenterology 2020. 
2. Villanueva A. Hepatocellular Carcinoma. N Engl J Med 2019; 380: 1450-1462.

3. Craig AJ, von Felden J, Garcia-Lezana T, Sarcognato S, Villanueva A. Tumour evolution in hepatocellular carcinoma. Nat Rev Gastroenterol Hepatol 2020; 17: 139-152.

4. Muller M, Bird TG, Nault JC. The landscape of gene mutations in cirrhosis and hepatocellular carcinoma. J Hepatol 2020; 72: 990-1002.

5. Wang G, Huang CH, Zhao Y, Cai L, Wang Y, Xiu SJ, et al. Genetic aberration in primary hepatocellular carcinoma: correlation between p53 gene mutation and loss-of-heterozygosity on chromosome 16q21-q23 and 9p21-p23. Cell Res 2000; 10: 311-323.

6. Adebayo Michael AO, Ko S, Tao J, Moghe A, Yang H, Xu M, et al. Inhibiting Glutamine-Dependent mTORC1 Activation Ameliorates Liver Cancers Driven by beta-Catenin Mutations. Cell Metab 2019; 29: 1135-1150 e1136.

7. Nahon P, Sutton A, Rufat P, Ziol M, Thabut G, Schischmanoff PO, et al. Liver iron, HFE gene mutations, and hepatocellular carcinoma occurrence in patients with cirrhosis. Gastroenterology 2008; 134: 102-110.

8. Ho DWH, Chan LK, Chiu YT, Xu IMJ, Poon RTP, Cheung TT, et al. TSC1/2 mutations define a molecular subset of HCC with aggressive behaviour and treatment implication. Gut 2017; 66: 14961506.

9. Yuen MF, Lau CS, Lau YL, Wong WM, Cheng CC, Lai CL. Mannose binding lectin gene mutations are associated with progression of liver disease in chronic hepatitis B infection. Hepatology 1999; 29: 1248-1251.

10. Yang H, Ni HM, Ding WX. The double-edged sword of MTOR in autophagy deficiency induced-liver injury and tumorigenesis. Autophagy 2019; 15: 1671-1673.

11. Chaturantabut S, Shwartz A, Evason KJ, Cox AG, Labella K, Schepers AG, et al. Estrogen Activation of G-Protein-Coupled Estrogen Receptor 1 Regulates Phosphoinositide 3-Kinase and mTOR Signaling to Promote Liver Growth in Zebrafish and Proliferation of Human Hepatocytes. Gastroenterology 2019; 156: 1788-1804 e1713.

12. Rebouissou S, Nault JC. Advances in molecular classification and precision oncology in hepatocellular carcinoma. J Hepatol 2020; 72: 215-229.

13. Ding X, He M, Chan AWH, Song QX, Sze SC, Chen H, et al. Genomic and Epigenomic Features of Primary and Recurrent Hepatocellular Carcinomas. Gastroenterology 2019; 157: 1630-1645 e1636.

14. Liang JQ, Teoh N, Xu L, Pok S, Li X, Chu ESH, et al. Dietary cholesterol promotes steatohepatitis related hepatocellular carcinoma through dysregulated metabolism and calcium signaling. Nat Commun 2018; 9: 4490.

15. Guri Y, Colombi M, Dazert E, Hindupur SK, Roszik J, Moes S, et al. mTORC2 Promotes Tumorigenesis via Lipid Synthesis. Cancer Cell 2017; 32: 807-823 e812.

16. Zheng YL, Li L, Jia YX, Zhang BZ, Li JC, Zhu YH, et al. LINC01554-Mediated Glucose Metabolism Reprogramming Suppresses Tumorigenicity in Hepatocellular Carcinoma via Downregulating PKM2 Expression and Inhibiting Akt/mTOR Signaling Pathway. Theranostics 2019; 9: 796-810. 
17. Maine GN, Burstein E. COMMD proteins: COMMing to the scene. Cell Mol Life Sci 2007; 64: 19972005.

18. Fernandez Masso JR, Oliva Arguelles B, Tejeda Y, Astrada S, Garay H, Reyes O, et al. The Antitumor Peptide CIGB-552 Increases COMMD1 and Inhibits Growth of Human Lung Cancer Cells. J Amino Acids 2013; 2013: 251398.

19. Thoms HC, Loveridge CJ, Simpson J, Clipson A, Reinhardt K, Dunlop MG, et al. Nucleolar targeting of RelA(p65) is regulated by COMMD1-dependent ubiquitination. Cancer Res 2010; 70: 139-149.

20. van de Sluis B, Mao X, Zhai Y, Groot AJ, Vermeulen JF, van der Wall E, et al. COMMD1 disrupts HIF1alpha/beta dimerization and inhibits human tumor cell invasion. J Clin Invest 2010; 120: 21192130.

21. Nakai A, Fujimoto J, Miyata H, Stumm R, Narazaki M, Schulz S, et al. The COMMD3/8 complex determines GRK6 specificity for chemoattractant receptors. J Exp Med 2019; 216: 1630-1647.

22. Suraweera A, Duff A, Adams MN, Jekimovs C, Duijf PHG, Liu C, et al. Defining COMMD4 as an anticancer therapeutic target and prognostic factor in non-small cell lung cancer. $\mathrm{Br} \mathrm{J}$ Cancer 2020.

23. Campion CG, Zaoui K, Verissimo T, Cossette S, Matsuda H, Solban N, et al. COMMD5/HCaRG Hooks Endosomes on Cytoskeleton and Coordinates EGFR Trafficking. Cell Rep 2018; 24: 670-684 e677.

24. Yang $M$, Huang $W$, Sun $Y$, Liang $H$, Chen $M, W u X$, et al. Prognosis and modulation mechanisms of COMMD 6 in human tumours based on expression profiling and comprehensive bioinformatics analysis. Br J Cancer 2019; 121: 699-709.

25. Zhan W, Wang W, Han T, Xie C, Zhang T, Gan M, et al. COMMD9 promotes TFDP1/E2F1 transcriptional activity via interaction with TFDP1 in non-small cell lung cancer. Cell Signal 2017; 30: 59-66.

26. Fan $Y$, Zhang $L$, Sun $Y$, Yang $M$, Wang $X$, Wu $X$, et al. Expression profile and bioinformatics analysis of COMMD10 in BALB/C mice and human. Cancer Gene Ther 2020; 27: 216-225.

27. Yang SS, Li XM, Yang M, Ren XL, Hu JL, Zhu XH, et al. FMNL2 destabilises COMMD10 to activate NFkappaB pathway in invasion and metastasis of colorectal cancer. Br J Cancer 2017; 117: 1164-1175.

28. Fedoseienko A, Wijers M, Wolters JC, Dekker D, Smit M, Huijkman N, et al. The COMMD Family Regulates Plasma LDL Levels and Attenuates Atherosclerosis Through Stabilizing the CCC Complex in Endosomal LDLR Trafficking. Circ Res 2018; 122: 1648-1660.

29. Goodall AH, Burns P, Salles I, Macaulay IC, Jones Cl, Ardissino D, et al. Transcription profiling in human platelets reveals LRRFIP1 as a novel protein regulating platelet function. Blood 2010; 116: 4646-4656.

30. Salehe BR, Jones Cl, Di Fatta G, McGuffin LJ. RAPIDSNPs: A new computational pipeline for rapidly identifying key genetic variants reveals previously unidentified SNPs that are significantly associated with individual platelet responses. PLoS One 2017; 12: e0175957.

31. Tang Z, Kang B, Li C, Chen T, Zhang Z. GEPIA2: an enhanced web server for large-scale expression profiling and interactive analysis. Nucleic Acids Res 2019; 47: W556-W560. 
32. Tang Z, Li C, Kang B, Gao G, Li C, Zhang Z. GEPIA: a web server for cancer and normal gene expression profiling and interactive analyses. Nucleic Acids Res 2017; 45: W98-W102.

33. Ning G, Huang YL, Zhen LM, Xu WX, Jiao Q, Yang FJ, et al. Transcriptional expressions of Chromobox $1 / 2 / 3 / 6 / 8$ as independent indicators for survivals in hepatocellular carcinoma patients. Aging (Albany NY) 2018; 10: 3450-3473.

34. Sanchez-Vega F, Mina M, Armenia J, Chatila WK, Luna A, La KC, et al. Oncogenic Signaling Pathways in The Cancer Genome Atlas. Cell 2018; 173: 321-337 e310.

35. Otasek D, Morris JH, Boucas J, Pico AR, Demchak B. Cytoscape Automation: empowering workflowbased network analysis. Genome Biol 2019; 20: 185.

36. Zheng L, Huang X, Liang P, Wen Y, Yang T, Li Y, et al. BC047440 overexpression is a risk factor for tumor invasion and poor prognosis in hepatocellular carcinoma. Hepatogastroenterology 2010; 57 : 919-925.

37. Zheng L, Liang P, Zhou J, Huang X, Wen Y, Wang Z, et al. BC047440 antisense eukaryotic expression vectors inhibited HepG2 cell proliferation and suppressed xenograft tumorigenicity. Braz J Med Biol Res 2012; 45: 97-103.

38. Zheng L, Liang P, Li J, Huang XB, Liu SC, Zhao HZ, et al. ShRNA-targeted COMMD7 suppresses hepatocellular carcinoma growth. PLoS One 2012; 7: e45412.

39. Lin Y, Bai L, Chen W, Xu S. The NF-kappaB activation pathways, emerging molecular targets for cancer prevention and therapy. Expert Opin Ther Targets 2010; 14: 45-55.

40. Su YL, Wang X, Mann M, Adamus TP, Wang D, Moreira DF, et al. Myeloid cell-targeted miR-146a mimic inhibits NF-kappaB-driven inflammation and leukemia progression in vivo. Blood 2020; 135 : 167-180.

41. Wang F, Yang JL, Yu KK, Xu M, Xu YZ, Chen L, et al. Activation of the NF-kappaB pathway as a mechanism of alcohol enhanced progression and metastasis of human hepatocellular carcinoma. Mol Cancer 2015; 14: 10.

42. Li Y, Lu L, Tu J, Zhang J, Xiong T, Fan W, et al. Reciprocal Regulation Between Forkhead Box M1/NFkB and Methionine Adenosyltransferase 1A Drives Liver Cancer. Hepatology 2020.

43. Kojok K, Akoum SE, Mohsen M, Mourad W, Merhi Y. CD40L Priming of Platelets via NF-kappaB Activation is CD40- and TAK1-Dependent. J Am Heart Assoc 2018; 7: e03677.

44. Qiu W, Hu J, Magnuson JT, Greer J, Yang M, Chen Q, et al. Evidence linking exposure of fish primary macrophages to antibiotics activates the NF-kB pathway. Environ Int 2020; 138: 105624.

45. Yamamoto K, Shioi T, Uchiyama K, Miyamoto T, Sasayama S, Matsumori A. Attenuation of virusinduced myocardial injury by inhibition of the angiotensin II type 1 receptor signal and decreased nuclear factor-kappa B activation in knockout mice. J Am Coll Cardiol 2003; 42: 2000-2006.

46. Li H, Chan L, Bartuzi P, Melton SD, Weber A, Ben-Shlomo S, et al. Copper metabolism domaincontaining 1 represses genes that promote inflammation and protects mice from colitis and colitisassociated cancer. Gastroenterology 2014; 147: 184-195 e183. 
47. Schulz R, McCole RB, Woodfine K, Wood AJ, Chahal M, Monk D, et al. Transcript- and tissue-specific imprinting of a tumour suppressor gene. Hum Mol Genet 2009; 18: 118-127.

48. Zoubeidi A, Ettinger S, Beraldi E, Hadaschik B, Zardan A, Klomp LW, et al. Clusterin facilitates COMMD1 and I-kappaB degradation to enhance NF-kappaB activity in prostate cancer cells. Mol Cancer Res 2010; 8: 119-130.

49. Zheng L, Deng CL, Wang L, Huang XB, You N, Tang YC, et al. COMMD7 is correlated with a novel NFkappaB positive feedback loop in hepatocellular carcinoma. Oncotarget 2016; 7: 32774-32784.

50. You N, Li J, Huang X, Wu K, Tang Y, Wang L, et al. COMMD7 activates CXCL10 production by regulating NF-kappaB and the production of reactive oxygen species. Mol Med Rep 2018; 17: 67846788.

51. Zheng L, You N, Huang X, Gu H, Wu K, Mi N, et al. COMMD7 Regulates NF-kappaB Signaling Pathway in Hepatocellular Carcinoma Stem-like Cells. Mol Ther Oncolytics 2019; 12: 112-123.

52. Chang JH, Kim YJ, Han SH, Kang CY. IFN-gamma-STAT1 signal regulates the differentiation of inducible Treg: potential role for ROS-mediated apoptosis. Eur J Immunol 2009; 39: 1241-1251.

53. Sharma S, Yang SC, Hillinger S, Zhu LX, Huang M, Batra RK, et al. SLC/CCL21-mediated anti-tumor responses require IFNgamma, MIG/CXCL9 and IP-10/CXCL10. Mol Cancer 2003; 2: 22.

54. Imam AM, Hamed AM, Nasef SI, Hassan AM, Omar HH. Biochemical Analysis of C-X-C Motif Chemokine Ligand 10 (CXCL10) as a Biomarker in Patients with Rheumatoid Arthritis. Egypt J Immunol 2019; 26: 79-86.

55. Abji F, Pollock RA, Liang K, Chandran V, Gladman DD. Brief Report: CXCL10 Is a Possible Biomarker for the Development of Psoriatic Arthritis Among Patients With Psoriasis. Arthritis Rheumatol 2016; 68: 2911-2916.

56. Paczesny S, Abu Zaid M. CXCL10: most consistent cGVHD biomarker? Blood 2016; 127: 2950-2951.

57. Brightling CE, Ammit AJ, Kaur D, Black JL, Wardlaw AJ, Hughes JM, et al. The CXCL10/CXCR3 axis mediates human lung mast cell migration to asthmatic airway smooth muscle. Am J Respir Crit Care Med 2005; 171: 1103-1108.

58. Yoshimatsu G, Kunnathodi F, Saravanan PB, Shahbazov R, Chang C, Darden CM, et al. Pancreatic beta-Cell-Derived IP-10/CXCL10 Isletokine Mediates Early Loss of Graft Function in Islet Cell Transplantation. Diabetes 2017; 66: 2857-2867.

59. Brownell J, Wagoner J, Lovelace ES, Thirstrup D, Mohar I, Smith W, et al. Independent, parallel pathways to CXCL10 induction in HCV-infected hepatocytes. J Hepatol 2013; 59: 701-708.

60. Ling CC, Ng KT, Shao Y, Geng W, Xiao JW, Liu H, et al. Post-transplant endothelial progenitor cell mobilization via CXCL10/CXCR3 signaling promotes liver tumor growth. J Hepatol 2014; 60: 103109.

61. Li CX, Ling CC, Shao Y, Xu A, Li XC, Ng KT, et al. CXCL10/CXCR3 signaling mobilized-regulatory T cells promote liver tumor recurrence after transplantation. J Hepatol 2016; 65: 944-952. 
62. Cheng AL, Hsu C, Chan SL, Choo SP, Kudo M. Challenges of combination therapy with immune checkpoint inhibitors for hepatocellular carcinoma. J Hepatol 2020; 72: 307-319.

63. Chow MT, Ozga AJ, Servis RL, Frederick DT, Lo JA, Fisher DE, et al. Intratumoral Activity of the CXCR3 Chemokine System Is Required for the Efficacy of Anti-PD-1 Therapy. Immunity 2019; 50: 1498-1512 e1495.

64. You N, Li J, Huang X, Wu K, Tang Y, Wang L, et al. COMMD7 promotes hepatocellular carcinoma through regulating CXCL10. Biomed Pharmacother 2017; 88: 653-657.

65. Harris DP, Bandyopadhyay S, Maxwell TJ, Willard B, DiCorleto PE. Tumor necrosis factor (TNF)-alpha induction of CXCL10 in endothelial cells requires protein arginine methyltransferase 5 (PRMT5)mediated nuclear factor (NF)-kappaB p65 methylation. J Biol Chem 2014; 289: 15328-15339.

66. Takabe P, Karna R, Rauhala L, Tammi M, Tammi R, Pasonen-Seppanen S. Melanocyte Hyaluronan Coat Fragmentation Enhances the UVB-Induced TLR-4 Receptor Signaling and Expression of Proinflammatory Mediators IL6, IL8, CXCL1, and CXCL10 via NF-kappaB Activation. J Invest Dermatol 2019; 139: 1993-2003 e1994.

67. Jin WJ, Kim B, Kim D, Park Choo HY, Kim HH, Ha H, et al. NF-kappaB signaling regulates cellautonomous regulation of CXCL10 in breast cancer 4T1 cells. Exp Mol Med 2017; 49: e295.

\section{Tables}


Table 1

Studies about COMMDs family proteins in different cancers and diseases

\begin{tabular}{|c|c|c|c|c|}
\hline $\begin{array}{l}\text { COMMD } \\
\text { proteins }\end{array}$ & Study & $\begin{array}{l}\text { Cancer and } \\
\text { disease type }\end{array}$ & $\begin{array}{l}\text { Regulated } \\
\text { factors or } \\
\text { pathway }\end{array}$ & Findings \\
\hline \multirow[t]{2}{*}{ COMMD1 } & $\begin{array}{l}\text { Masso JR } \\
\text { et al., } \\
2013 \text { [18] }\end{array}$ & Lung cancer & $\begin{array}{l}\text { NF-kB } \\
\text { pathway }\end{array}$ & $\begin{array}{l}\text { COMMD1inhibited NF-KB activity and } \\
\text { decreased the activation of } \\
\text { antiapoptotic genes }\end{array}$ \\
\hline & $\begin{array}{l}\text { Burstein et } \\
\text { al., } 2010 \\
{[20]}\end{array}$ & $\begin{array}{l}\text { Pancreatic } \\
\text { cancer, } \\
\text { ovarian } \\
\text { cancer, breast } \\
\text { cancer }\end{array}$ & HIF-1a & $\begin{array}{l}\text { COMMD1 prevented the dimerization } \\
\text { of HIF- } 1 \mathrm{a} \text { and HIF- } 1 \beta \text { and } \\
\text { subsequent DNA binding and } \\
\text { transcriptional activation }\end{array}$ \\
\hline COMMD3/8 & $\begin{array}{l}\text { Suzuki et } \\
\text { al., } 2019 \\
{[21]}\end{array}$ & $\begin{array}{l}\text { Humoral } \\
\text { immune } \\
\text { responses }\end{array}$ & $\begin{array}{l}\beta \text {-arrestin- } \\
\text { mediated } \\
\text { signaling }\end{array}$ & $\begin{array}{l}\text { COMMD3/8 complex selectively } \\
\text { recruited GRK6 and induced GRK6- } \\
\text { mediated phosphorylation of the } \\
\text { receptor and activation of } \beta \text {-arresti- } \\
\text { mediated signaling }\end{array}$ \\
\hline COMMD4 & $\begin{array}{l}\text { Suraweera } \\
\text { et al., } \\
2020 \text { [22] }\end{array}$ & $\begin{array}{l}\text { Non-small cell } \\
\text { lung cancer } \\
\text { (NSCLC) }\end{array}$ & $\begin{array}{l}\text { Not } \\
\text { mentioned }\end{array}$ & $\begin{array}{l}\text { COMMD } 4 \text { expressed higher in NSCLC } \\
\text { and promoted cell proliferation }\end{array}$ \\
\hline COMMD5 & $\begin{array}{l}\text { Campion } \\
\text { et al., } \\
2018 \text { [23] }\end{array}$ & $\begin{array}{l}\text { Renal clear } \\
\text { cell } \\
\text { carcinoma } \\
\text { (RCC) }\end{array}$ & EGFR & $\begin{array}{l}\text { COMMD } 5 \text { inhibited the growth of } \\
\text { renal carcinoma cells by regulating } \\
\text { EGFR trafficking }\end{array}$ \\
\hline COMMD6 & $\begin{array}{l}\text { Yang et } \\
\text { al., } 2019 \\
\text { [24] }\end{array}$ & $\begin{array}{l}\text { Liver cancer, } \\
\text { lung cancer, } \\
\text { etc. }\end{array}$ & $\begin{array}{l}\text { NF-kB } \\
\text { pathway }\end{array}$ & $\begin{array}{l}\text { High expression of COMMD6 related } \\
\text { with poor prognosis of tumors }\end{array}$ \\
\hline COMMD7 & $\begin{array}{l}\text { Zheng et } \\
\text { al., 2012 } \\
\text { [33] }\end{array}$ & $\begin{array}{l}\text { Hepatocellular } \\
\text { carcinoma }\end{array}$ & $\begin{array}{l}\text { NF-kB } \\
\text { pathway }\end{array}$ & $\begin{array}{l}\text { COMMD7 promoted the progression } \\
\text { of HCC by negatively regulating NF- } \\
\text { KB pathway }\end{array}$ \\
\hline COMMD9 & $\begin{array}{l}\text { Zhan et } \\
\text { al., } 2017 \\
{[25]}\end{array}$ & NSCLC & TFDP1/E2F1 & $\begin{array}{l}\text { High expression of COMMD9 led to } \\
\text { advanced NSCLC }\end{array}$ \\
\hline COMMD10 & $\begin{array}{l}\text { Yang et } \\
\text { al., 2017 } \\
\text { [26] }\end{array}$ & $\begin{array}{l}\text { RCC, } \\
\text { Colorectal } \\
\text { cancer }\end{array}$ & $\begin{array}{l}\text { NF-KB } \\
\text { pathway }\end{array}$ & $\begin{array}{l}\text { COMMD } 10 \text { inhibited the invasion and } \\
\text { metastasis of colorectal cancer by } \\
\text { promoting ubiquitination and } \\
\text { degradation of NF-kB }\end{array}$ \\
\hline
\end{tabular}


Table 2

Top ten positively correlated genes of COMMD7 in HCC

\begin{tabular}{|llll|}
\hline Positively correlated Gene & Cytoband & Spearman's correlation & p-Value \\
\hline DYNLRB1 & $20 \mathrm{q} 11.22$ & 0.699 & $4.58 \mathrm{e}-56$ \\
\hline PDRG1 & $20 \mathrm{q} 11.21$ & 0.674 & $1.00 \mathrm{e}-50$ \\
\hline MANBAL & $20 \mathrm{q} 11.23$ & 0.646 & $2.18 \mathrm{e}-45$ \\
\hline PFDN4 & $20 \mathrm{q} 13.2$ & 0.643 & $5.86 \mathrm{e}-45$ \\
\hline RALY & $20 \mathrm{q} 11.22$ & 0.630 & $1.12 \mathrm{e}-42$ \\
\hline CHMP4B & $20 \mathrm{q} 11.22$ & 0.628 & $2.68 \mathrm{e}-42$ \\
\hline MRGBP & $20 \mathrm{q} 13.33$ & 0.628 & $2.92 \mathrm{e}-42$ \\
\hline PIGU & $20 \mathrm{q} 11.22$ & 0.627 & $3.45 \mathrm{e}-42$ \\
\hline ARPC4 & $3 \mathrm{p} 25.3$ & 0.627 & $4.52 \mathrm{e}-42$ \\
\hline ROM01 & $20 \mathrm{q} 11.22$ & 0.620 & $4.57 \mathrm{e}-41$ \\
\hline
\end{tabular}

Table 3

Top ten negatively correlated genes of COMMD7 in HCC

\begin{tabular}{|llll|}
\hline Negatively correlated Gene & Cytoband & Spearman's correlation & p-Value \\
\hline ABHD18 & $4 q 28.2$ & -0.657 & $1.73 \mathrm{e}-47$ \\
\hline ERN1 & $17 \mathrm{q} 23.3$ & -0.653 & $1.22 \mathrm{e}-46$ \\
\hline DDI2 & $1 \mathrm{p} 36.21$ & -0.627 & $3.89 \mathrm{e}-42$ \\
\hline USP12 & $13 \mathrm{q} 12.13$ & -0.625 & $7.01 \mathrm{e}-42$ \\
\hline METTL14 & $4 \mathrm{q} 26$ & -0.613 & $7.37 \mathrm{e}-40$ \\
\hline TOR1AIP2 & $1 \mathrm{q} 25.2$ & -0.605 & $1.18 \mathrm{e}-38$ \\
\hline PPTC7 & $12 \mathrm{q} 24.11$ & -0.602 & $3.59 \mathrm{e}-38$ \\
\hline MAP3K2 & $2 \mathrm{q} 14.3$ & -0.601 & $6.08 \mathrm{e}-38$ \\
\hline RSC1A1 & $1 \mathrm{p} 36.21$ & -0.601 & $6.17 \mathrm{e}-38$ \\
\hline ZNF281 & $1 \mathrm{q} 32.1$ & -0.594 & $5.43 \mathrm{e}-37$ \\
\hline
\end{tabular}


HEPATOCELLULAR CARCINOMA

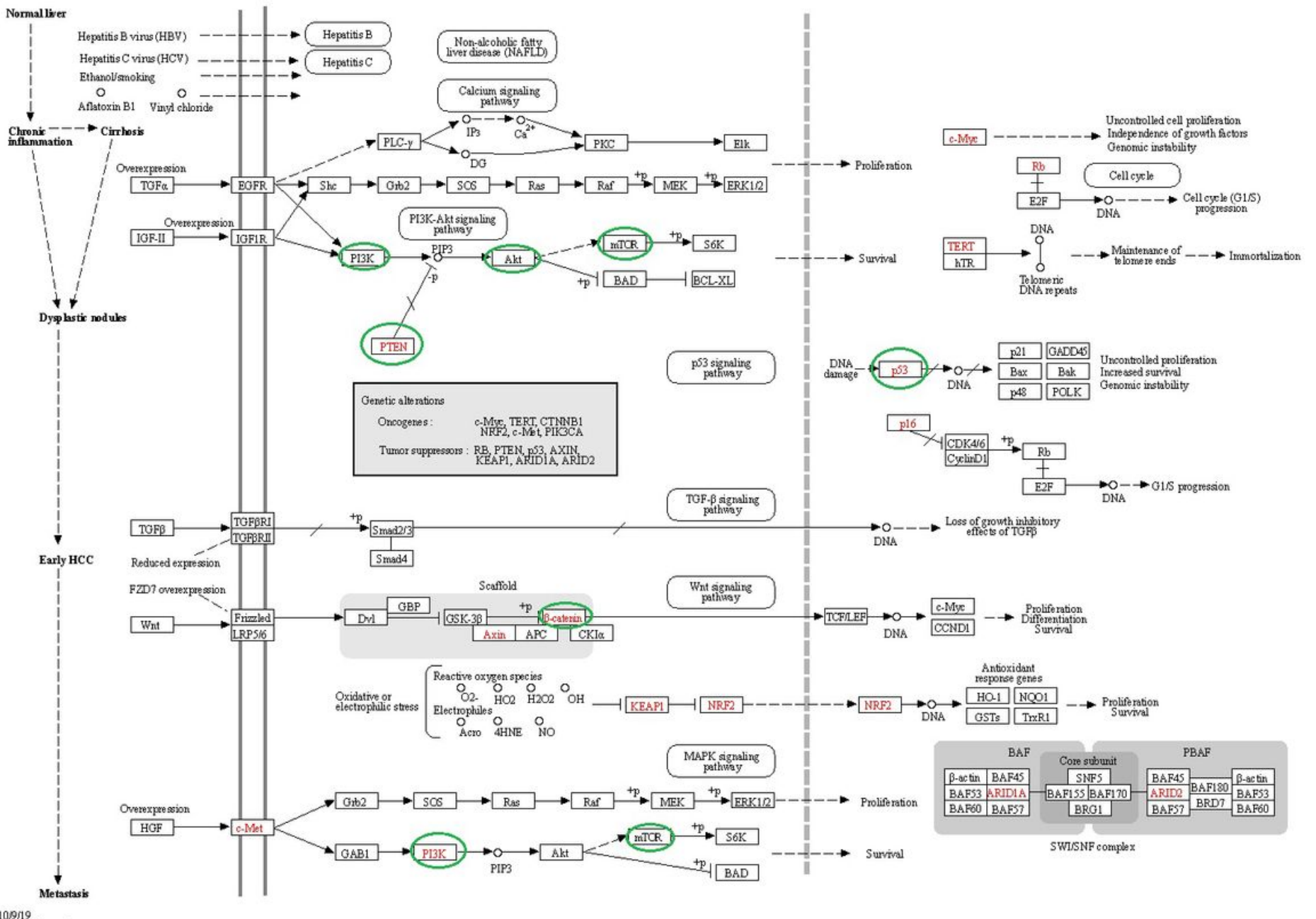

05225109119
$(c)$ Kanehisa Laboratories

\section{Figure 1}

The map of signaling pathways and key factors involved in hepatocellular carcinoma (https://www.genome.jp/kegg/). 

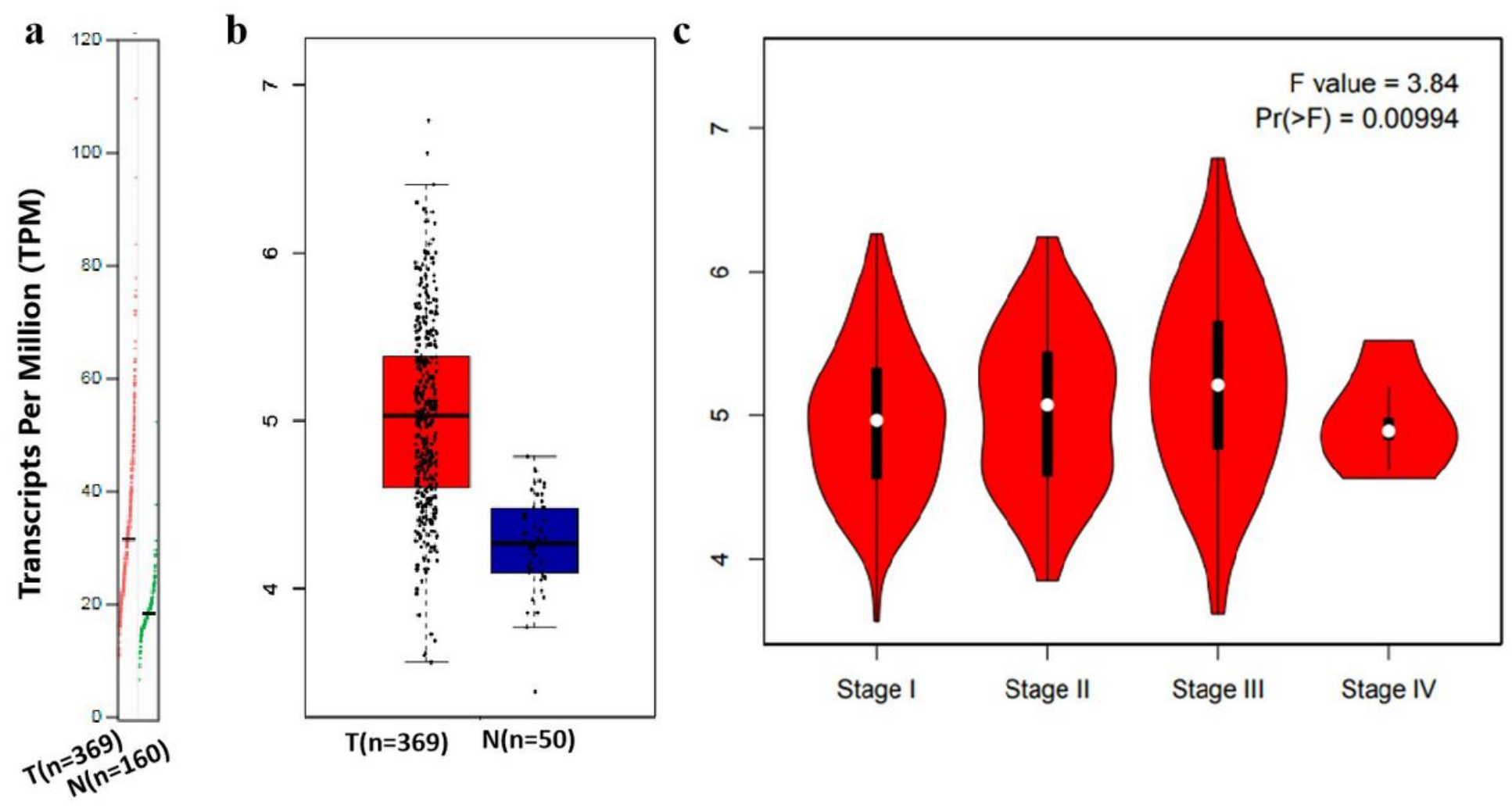

\section{Figure 2}

The expression profile of COMMD7 in HCC (GEPIA). (a) Transcription level of COMMD7 in tumor(T) and non-tumor(N) samples. (b) Relative protein level of COMMD7 in tumor(T) and non-tumor(N) samples; (c) Correlation between COMMD7 expression and tumor stage in HCC patients.

a

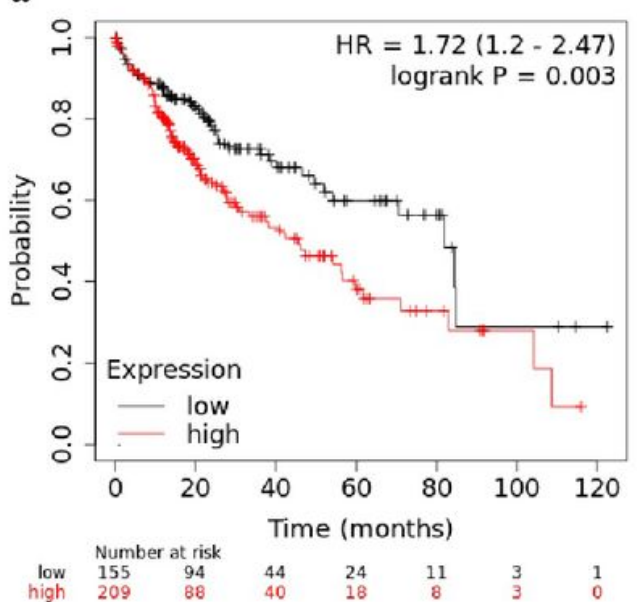

b

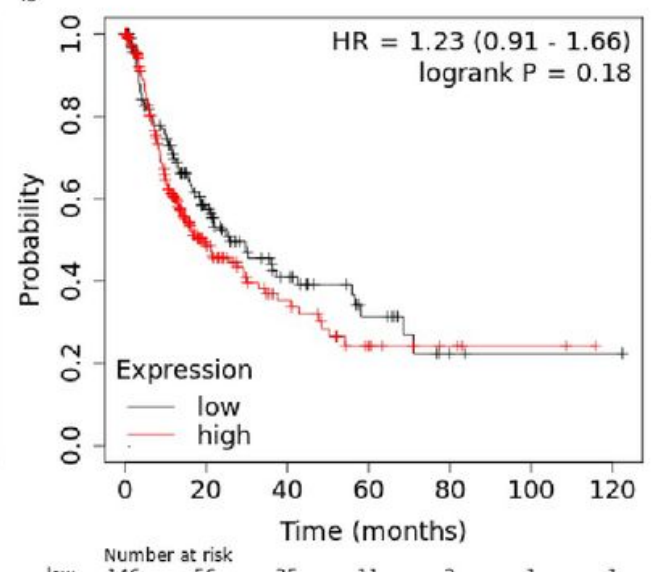

c

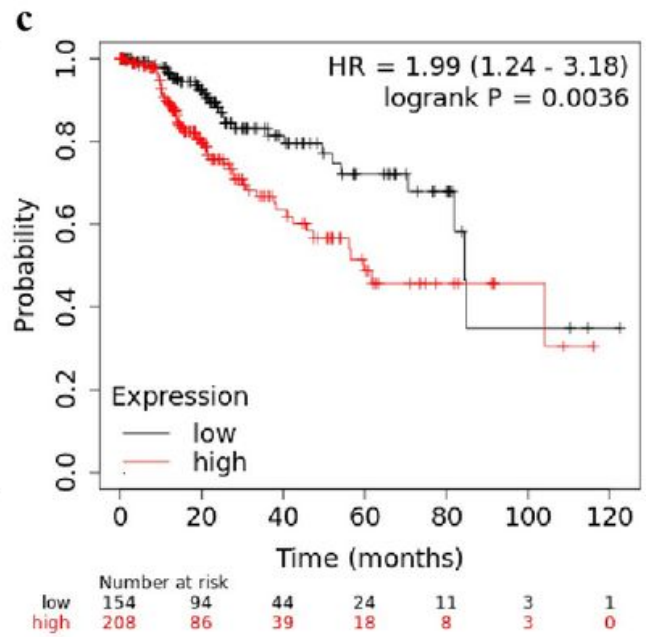

\section{Figure 3}

The prognostic value of mRNA level of COMMD7 in HCC patients (Kaplan-Meier plotter). The correlation between COMMD7 mRNA expression level and overall survival (OS)(a), progress-free survival(PFS)(b), and recurence-free survival(RFS)(c). 
$\mathbf{a}$

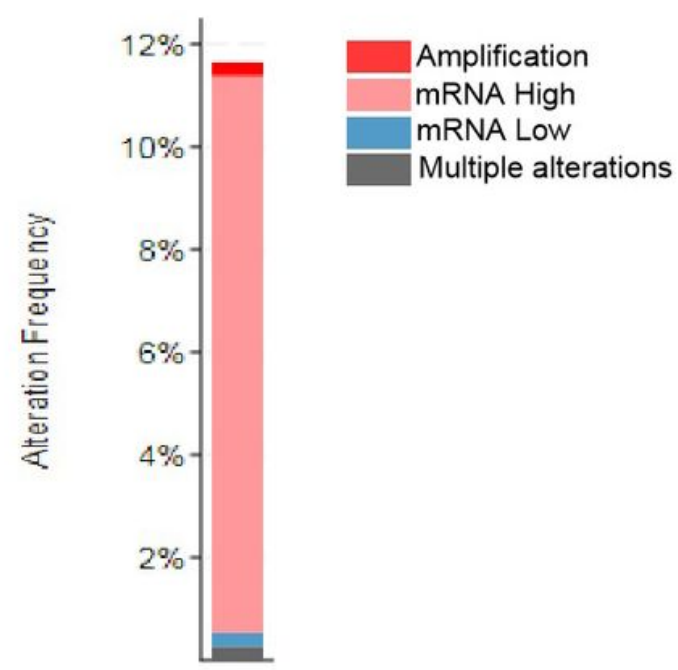

d

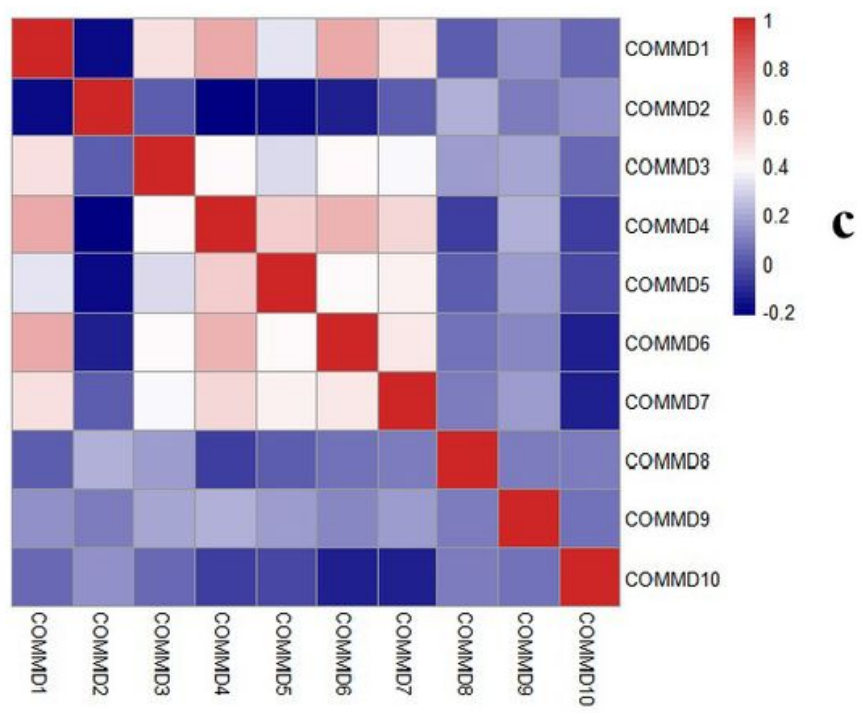

b

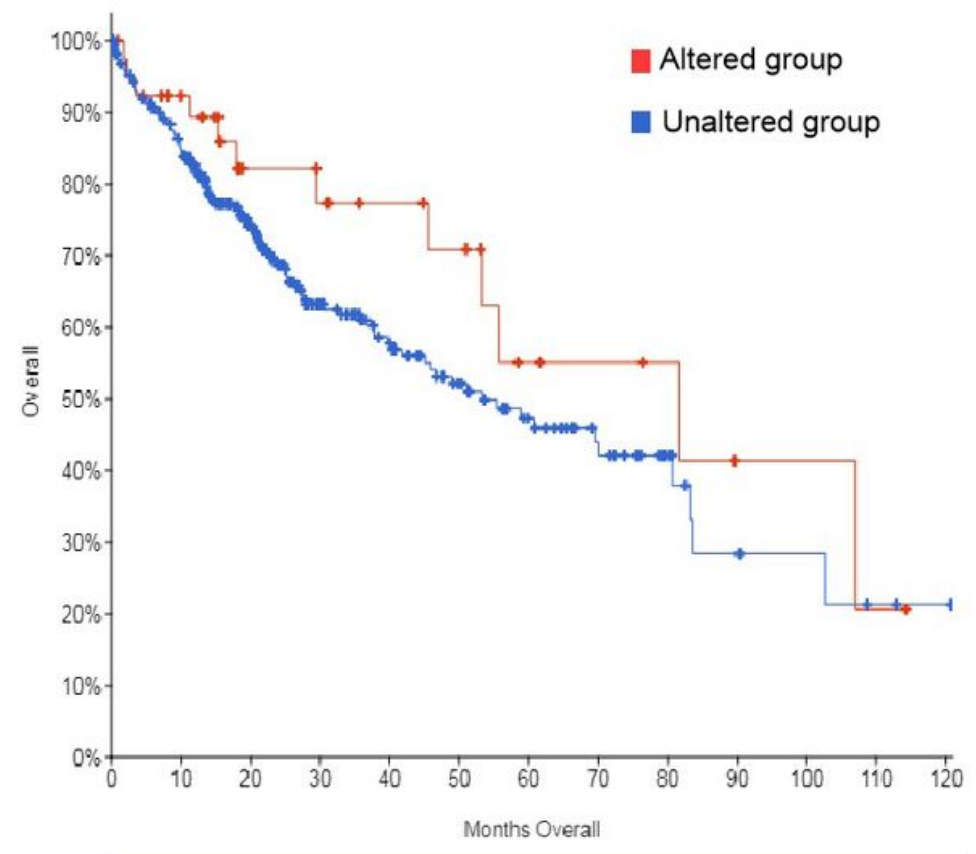

\begin{tabular}{|cccc|}
\hline & $\begin{array}{c}\text { Number of } \\
\text { Cases, Total }\end{array}$ & $\begin{array}{c}\text { Number of } \\
\text { Cases, } \\
\text { Deceased }\end{array}$ & $\begin{array}{c}\text { Median } \\
\text { Months } \\
\text { Overall }\end{array}$ \\
\hline $\begin{array}{c}\text { Altered } \\
\text { group }\end{array}$ & 42 & 12 & 81.67 \\
$\begin{array}{c}\text { Unalter } \\
\text { ed } \\
\text { group }\end{array}$ & 328 & 118 & 53.35 \\
\hline
\end{tabular}

\section{Figure 4}

COMMD7 gene expression and mutation analysis in hepatocellular carcinoma (cBioPortal). (a) Gene mutation types in HCC; (b) Correlation between COMMD7 alteration and patients survival; (c) COMMD7altered cases and survival time of HCC patients; (d) Pearson's correction among the 10 COMMDs family members. 
a

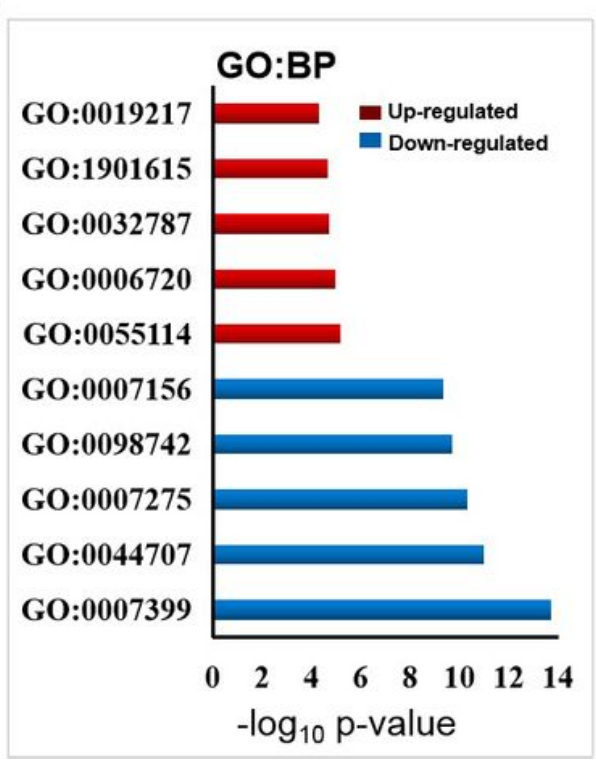

b

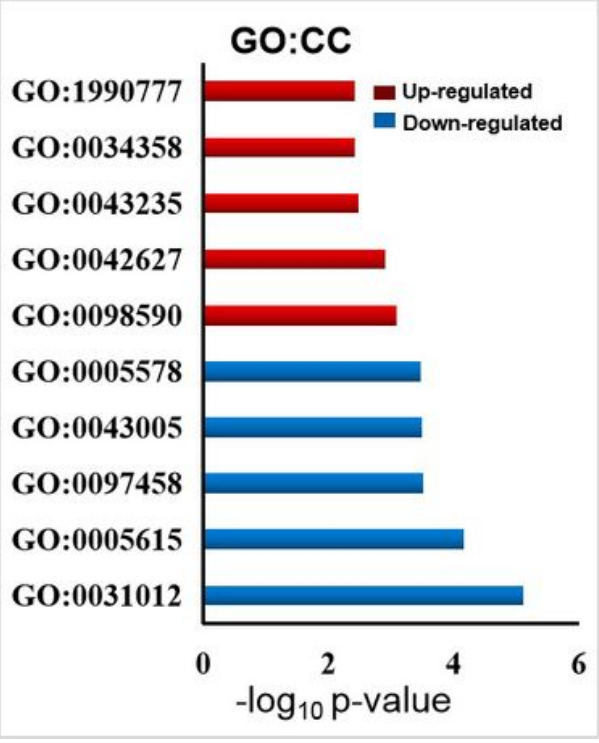

c

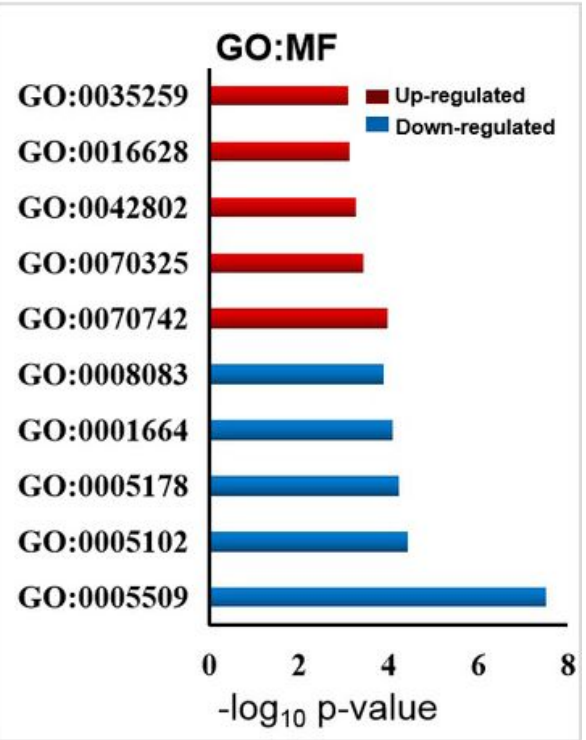

\section{Figure 5}

The functions of COMMD7 genes in liver cancer stem cells. (https://david.ncifcrf.gov/summary.jsp). GO enrichment analysis predicted the functional roles of COMMD7 based on three aspects including biological processes (a), cellular components (b), and molecular functions (c). 